AIAA 97-2569

Transition Effects on Heating

in the Wake of a Blunt Body

Brian R. Hollis, John N. Perkins

North Carolina State University

Raleigh, NC 27695

Grants NAG1-1663 and NAGW-1331

Prepared for NASA Langley Research Center

32nd AIAA Thermophysics Conference

June 23-25, 1997 / Atlanta, GA 


\title{
Transition Effects on Heating in the Wake of a Blunt Body
}

\author{
Brian R. Hollis* and John N. Perkins** \\ Department of Mechanical and Aerospace Engineering \\ North Carolina State University \\ Raleigh, NC 27695-7910
}

\begin{abstract}
A series of aerodynamic heating tests was conducted A on a 70-deg sphere-cone planetary entry vehicle model in a Mach 10 perfect-gas wind tunnel at freestream Reynolds numbers based on diameter of $8.23 \times 10^{4}$ to $3.15 \times 10^{5}$. Surface heating distributions were determined from temperature time-histories measured on the model and on its support sting using thin-film resistance gages. The experimental heating data were compared to computations made using an axisymmetric/2D, laminar, perfect-gas Navier-Stokes solver. Agreement between computational and experimental heating distributions to within, or slightly greater than, the experimental uncertainty was obtained on the forebody and afterbody of the entry vehicle as well as on the sting upstream of the free-shear-layer reattachment point. However, the distributions began to diverge near the reattachment point, with the experimental heating becoming increasingly greater than the computed heating with distance downstream from the reattachment point. It was concluded that this divergence was due to transition of the wake free shear layer just upstream of the reattachment point on the sting.
\end{abstract}

\begin{tabular}{ll} 
& \multicolumn{1}{c}{ Nomenclature } \\
$B_{C, H}$ & heating bias error \\
$C_{H}$ & Stanton number, $q /\left[\rho_{1} u_{1}\left(h_{0}-h_{w}\right)\right]$ \\
$d$ & molecular diameter $(\mathrm{m})$ \\
$h$ & enthalpy $(\mathrm{J} / \mathrm{kg})$ \\
$K n$ & Knudsen number \\
$k$ & thermal conductivity $(\mathrm{W} / \mathrm{m}-\mathrm{K})$ \\
$M$ & Mach number
\end{tabular}

* Research performed as graduate research assistant. Presently National Research Council Research Associate, NASA Langley Research Center. AIAA Member.

** Professor of Mechanical and Aerospace Engineering. AIAA

Associate Fellow

\author{
$N \quad$ number density $\left(1 / \mathrm{m}^{3}\right)$ \\ $P_{C, H} \quad$ heating precision error \\ $p \quad$ pressure $\left(\mathrm{N} / \mathrm{m}^{2}\right)$ \\ $Q \quad$ heat $\left(\mathrm{J} / \mathrm{m}^{2}\right)$ \\ $q \quad$ heat transfer rate $\left(\mathrm{W} / \mathrm{m}^{2}\right)$ \\ $R \quad$ radius (m) \\ Re Reynolds number \\ $S \quad$ distance along model surface (m) \\ $T \quad$ temperature (K) \\ $t \quad$ time (sec) \\ $U_{\infty} \quad$ freestream velocity $(\mathrm{m} / \mathrm{sec})$ \\ $\alpha \quad$ thermal diffusivity $\left(\mathrm{m}^{2} / \mathrm{sec}\right)$ \\ $\beta \quad$ thermal product, $\alpha / \sqrt{k}\left(\mathrm{~W}-\sec ^{1 / 2} / \mathrm{m}^{2}-\mathrm{K}\right)$ \\ $\Delta C_{H} \quad$ heating uncertainty \\ $\lambda \quad$ correction factor $(1 / \mathrm{K})$ \\ $\lambda_{M F P} \quad$ mean free path $(\mathrm{m})$ \\ $\rho \quad$ density $\left(\mathrm{kg} / \mathrm{m}^{3}\right)$
}

Subscripts:

$\begin{array}{ll}0 & \text { stagnation } \\ 1 & \text { freestream } \\ 2 & \text { post-shock } \\ D & \text { diameter } \\ w & \text { wall }\end{array}$

\section{Introduction}

Wake flow behavior is one of the important issues which must be considered in the design of planetary entry vehicles such as the Mars Pathfinder probe $^{1}$. The nature of the wake flow dictates payload size, placement and shielding requirements. Accurate characterization of the wake flow behavior is becoming

Copyright $\odot 1997$ by the American Institute of Aeronautics and Astronautics, Inc. All rights reserved 
more important due to the increasing reliance in planetary mission planning on aerobraking, which produces much more severe aerothermodynamic loads on an entry vehicle.

In this study, the effects of transition in the wake of a blunt body were investigated through heattransfer testing of a 70-deg sphere-cone entry vehicle configuration in a perfect-gas hypersonic wind tunnel. Other recent studies ${ }^{2-15}$ have also addressed the effects of nonequilibrium thermochemistry, rarefaction, and transition to turbulence on wake flow behavior.

\section{Test Models}

\section{Experiment Description}

The test model geometry was a 70-deg spherecone forebody of 1.0 -in. radius with a 40 -deg conefrustrum afterbody (Fig. 1). The forebody corner radius was 0.05 forebody radii, and the radius of the hemispherical nose was 0.5 forebody radii. The afterbody frustrum radius was 0.6 forebody radii.

A heat-transfer test model was fabricated from Macor, a thermally-insulative, machinable glass-ceramic material. The model was instrumented with fastresponse $(<1 \mu \mathrm{sec})$ thin-film temperature resistance gages. There were a total of 37 gages on the forebody, afterbody and base of the model (Fig. 2). The support sting for this model was fabricated from stainless steel. A lengthwise slot into which a contoured Macor insert with 33 additional thin-film gages was fitted was machined into the sting (Fig. 2). The support sting was fitted to a sting adapter and the facility support barrel at a distance of 5.25 forebody radii downstream of the model. An additional uninstrumented model and sting were fabricated from aluminum for use in oil-flow tests.

\section{Facility Description}

Aerothermodynamic testing was conducted in the NASA Langley Research Center (LaRC) 31-Inch Mach 10 Air Tunnel ${ }^{16}$ (Fig. 3). This facility is a conventional perfect-gas hypersonic blowdown wind tunnel in which air is used as the test gas. The 31-Inch Mach 10 Air Tunnel has been calibrated for operation at reservoir pressures of $0.86 \mathrm{MPa}$ to $10 \mathrm{MPa}$ at a reservoir temperature of $1000 \mathrm{~K}$. These reservoir conditions produce freestream Reynolds numbers of from $1.62 \times 10^{6} \mathrm{~m}^{-1}$ to $6.20 \times 10^{6} \mathrm{~m}^{-1}$ at a nominal freestream Mach number of 10. Facility run times for the current series of heat-transfer tests were limited to 35 seconds in order to avoid violation of the semi-infinite heat transfer assumption ${ }^{17}$, although much longer run times are possible for aerodynamic testing. Freestream conditions for this study are listed in Table 1 . The runto-run repeatability of the facility flow conditions was investigated, and it was found that the freestream conditions were repeatable to within less than $\pm 2 \%$.

\section{Data Reduction}

Heat-transfer rate time-histories were computed from thin-film gage temperature time-histories using the 1 DHEAT data reduction code ${ }^{18}$. Heating timehistories were determined from the temperature timehistories by two methods: the Kendall-Dixon method ${ }^{19}$, which is a closed-form analytical scheme; and a numerical solution of the one-dimensional heatconduction equation. Both methods are based on the assumption of one-dimensional heat conduction within the model substrate ${ }^{17}$.

In the Kendall-Dixon method, the total heat energy added as a function of time is first computed by:

$$
Q\left(t_{n}\right)=\frac{\beta}{\sqrt{\pi}} \sum_{i=1}^{n} \frac{\left(T_{i}-T_{1}\right)+\left(T_{i-1}-T_{1}\right)}{\sqrt{t_{n}-t_{i}}+\sqrt{t_{n}-t_{i-1}}} \Delta t
$$

After the total heat added has been computed, the heattransfer rate is computed from ${ }^{20}$ :

$$
q\left(t_{n}\right)=\frac{d Q\left(t_{n}\right)}{d t}=\frac{-2 Q_{n-8}-Q_{n-4}+Q_{n+4}+2 Q_{n+8}}{40 \Delta t}(2)
$$

It is assumed in the derivation of the KendallDixon method that the thermal properties of the model remain constant. However, the thermal properties of Macor are functions of temperature. Curve fits to experimental thermal properties data ${ }^{18}$ are given by:

$$
\begin{gathered}
\rho=2543\left(\mathrm{~kg} / \mathrm{m}^{3}\right) \\
k=0.33889+7.4682 \times 10^{-3} T-1.6118 \times 10^{-5} T^{2} \\
+1.2376 \times 10^{-8} T^{3}(\mathrm{~W} / \mathrm{m}-\mathrm{K}) \\
\alpha=1.3003 \times 10^{-6}-2.2523 \times 10^{-9} T+ \\
1.8571 \times 10^{-12} T^{2}\left(\mathrm{~m}^{2} / \mathrm{sec}\right)
\end{gathered}
$$

The results from the Kendall-Dixon method are adjusted to account for the temperature dependence 
through an empirical correction given by ${ }^{18}$ :

$$
q_{v a r}=q_{c o n s t}\left[1+\lambda\left(T_{w}-300\right)\right]
$$

where the correction factor $\lambda$ is given by:

$$
\lambda=7.380 \times 10^{-4}-4.604 \times 10^{-7}\left(T_{w}-300\right)
$$

This empirical correction can be avoided through the use of the numerical method, in which the variation of thermal properties with temperature is included in the formulation of the method. In this numerical method, the one-dimensional heat conduction equation:

$$
\rho c_{p} \frac{\partial T}{\partial t}=\frac{\partial}{\partial x}\left(k \frac{\partial T}{\partial x}\right)
$$

is solved through a time-implicit, finite-volume discretization given by:

$$
\begin{gathered}
{\left[-k_{\mathrm{i}-1 / 2} \frac{\left(T_{i}^{n}-T_{i-1}^{n}\right)}{\left(x_{i}-x_{i-1}\right)}\right]-\left[-k_{\mathrm{i}+1 / 2} \frac{\left(T_{i+1}^{n}-T_{i}^{n}\right)}{\left(x_{i+1}-x_{i}\right)}\right]=} \\
{\left[\left(\rho c_{p}\right)_{i} \frac{\left(T_{i}^{n}-T_{i}^{n-1}\right)}{\Delta t}\right]\left(x_{i+1 / 2}-x_{i-1 / 2}\right)}
\end{gathered}
$$

The Kendall-Dixon method was used for rapid initial analysis of the experimental data. The validity of the empirical correction in this method was later verified by re-reducing the data using the finite-volume method.

\section{Experimental Results}

The 70-deg sphere-cone heat-transfer model was tested in the 31-Inch Mach 10 Air Tunnel at diameterbased freestream Reynolds numbers of $8.23 \times 10^{4}$, $1.62 \times 10^{5}$, and $3.15 \times 10^{5}$. The experimental data are reported in terms of the Stanton number which is defined by:

$$
C_{H}=\frac{q}{\rho_{1} U_{1}\left(h_{0}-h_{w}\right)}
$$

The Stanton number remains nominally constant during a test, whereas the heat-transfer rate decreases as the wall surface temperature and enthalpy increases.

Stanton number distributions normalized by the measured stagnation point values from tests at each of the three Reynolds number test points are plotted in Figs. 4 and 5. The complete distributions are shown on a log scale in Fig. 4, while the details of the forebody and wake distributions are shown separately on linear scale plots in Fig. 5. The Reynolds number had no effect on the normalized forebody heating distribution, but had a strong influence on the heating distribution in the wake, where the normalized heating was an increasing function of Reynolds number. The peak heating on the model sting varied from $8 \%$ of the forebody stagnation point heating at the lowest Reynolds number to $15 \%$ at the highest Reynolds number. Relative peak sting heating rates of this level are consistent with turbulent wakes $6,7,14$, whereas relative laminar peak sting heating levels are in the 4$5 \%$ range ${ }^{12-15}$.

Several surface oil flow tests were also carried out using the uninstrumented aluminum model. From inspection of oil flow photographs from these tests, it was possible to identify the boundary-layer separation point on the afterbody and the free-shear-layer reattachment point on the sting. A sample surface oil flow photograph is shown in Fig. 6. It was found that the reattachment point on the sting moved a small distance upstream toward the model as the Reynolds number was increased. This behavior is typical of increasing turbulence in the free shear layer. As the turbulence increases, momentum dissipation causes its thickness to increase, and the thicker turbulent free shear layer then comes into contact with the sting further upstream than a laminar free shear layer would.

\section{Experimental Uncertainty}

Two primary sources of experimental uncertainty were considered: precision error, $P_{C, H}$, due to run-to-run repeatability of flow conditions and test data, and bias error, $B_{C, H}$, due to uncertainty in the thermal properties of the Macor models. From these two sources, the overall uncertainty, $\Delta C_{H}$, was estimated as:

$$
\frac{\Delta C_{H}}{C_{H}}=t_{95} \sqrt{\left(\frac{B_{C, H}}{C_{H}}\right)^{2}+\left(\frac{P_{C, H}}{C_{H}}\right)^{2}}
$$

As per the AIAA Standards Committee recommendations ${ }^{21}$, the value of the 95th percentile point of the two-tailed Student's "t" distribution was set to $t_{95}=2$, which is the limit for an infinite number of data points. Due to the high flow quality of the 31-Inch 
Mach 10 Air Tunnel, the precision error in run-to-run repeatability was only on the order of $\pm 1-2 \%$. From thermal properties calibration test data reported in Ref. 18 , the thermal properties bias error was estimated to be on the order of $\pm 3 \%$. The overall total uncertainty for heating in this study was thus estimated to be on the order of $\pm 7-8 \%$.

\section{Code Description}

\section{Computations}

Flow field solutions for the 70-deg sphere-cone geometry were generated using the laminar, axisymmetric/2D Navier-Stokes solver NEQ2D ${ }^{22}$. A perfect gas thermochemical model was used to reproduce conditions equivalent to those of the 31-Inch Mach 10 Air Tunnel tests, although NEQ2D does also incorporate nonequilibrium thermochemical models. The governing equations are solved in NEQ2D through the line Gauss-Seidel method. Inviscid fluxes are represented by a modified form ${ }^{23}$ of the Beam-Warming flux-splitting technique which minimizes the numerical dissipation produced in boundary layers by the original form. Viscous fluxes are represented by central secondorder differences.

\section{Grid Generation, Adaptation and Resolution}

An initial grid of 125 streamwise by 90 normal points for the sphere-cone geometry was created using an elliptical grid generation algorithm ${ }^{24}$. Orthogonality and initial cell spacing at the wall were enforced through Steger-Sorenson ${ }^{25}$ boundary conditions. During computation of a solution, the grid was aligned with the bow shock and cells were clustered at the wall using an algebraic adaptation algorithm developed by Gnoffo ${ }^{26}$.

It was found that the wake computations were extremely sensitive to the structure of the wake grid. This sensitivity is due to the fact the wake free shear layer and recirculation vortex are viscous-dominated regions. Grid resolution in the wake vortex and free shear layer must be of the same order as found in attached wall boundary layers in order to properly resolve the flow field gradients in these regions.

In order to optimize the wake grid structure, the Volume Grid Manipulator ${ }^{27}$ (VGM) code was used to cluster grid points within the recirculation vortex and to align the streamwise grid lines with the free shear layer (Fig. 7) after an initial flow field solution was computed. This adaptation produced significant changes in the structure of the wake flow field. As seen in Fig.
8 , the free-shear-layer reattachment point on the wakeadapted grid moved downstream from the computed location on the unadapted grid and so the recirculation vortex grew larger. This growth in the wake vortex size is due the fact that numerical dissipation produced by the lack of resolution within the wake vortex is minimized by the adaptation of the wake grid through VGM.

In addition to the effects of the wake grid structure on the computed solutions, the effects of grid point density were also investigated. Flow field solutions were found to be relatively insensitive to streamwise grid resolution as compared to the sensitivity to normal grid resolution. Therefore, to investigate the effects of normal grid point resolution on the solution, grids with 125 streamwise points and 45,179 , and 357 normal points were constructed from the baseline (125 x 90) point shear-layer-adapted grid.

The forebody computations (Fig. 9a) were relatively insensitive to normal grid point resolution. The greatest sensitivity was observed around the nose and corner heating peaks, where the heating rates decreased by less than $5 \%$ between the 45 and 90 normal points grids, and by $\sim 1 \%$ between the 90 and 179 point grids.

Wake computations (Fig. 9b) were much more sensitive to grid resolution than forebody computations, as would expected given the much larger viscous region to be resolved in the wake. The sensitivity was greatest on the part of the sting bounded by the recirculation vortex, while the results on the portions of the afterbody and sting over which the flow was attached showed less sensitivity. On the portion of the sting within the wake vortex, heating rates decreased by more than $10 \%$ between the 45 and 90 normal point grids, by $5-10 \%$ between the 90 and 179 point grids, and by less than $5 \%$ between the 179 and 357 point grids.

From these grid resolution results it was concluded that 90 normal points were more than sufficient to model the forebody flow and the attached flow on the afterbody and on the sting downstream of the vortex. However, acceptable results were achieved within the recirculation vortex only on the highest resolution, 357 normal point grid.

\section{Computational Results}

Solutions were computed for each of the three Reynolds number operating points on shear-layeradapted, (125 x 357) point grids using the NEQ2D code. Freestream flow conditions were taken from Table 1, 
and a uniform $300 \mathrm{~K}$ wall temperature was specified. These computations revealed complex recirculating flow patterns in the near wake of the body. As shown in Fig. 10, a large main vortex was generated between the free shear layer and body. Smaller counter-rotating vortices were also produced at the base of the vehicle and on the afterbody. The size of the main vortex increased with Reynolds number, which is the theoretically-expected behavior in a laminar wake: as the Reynolds number is increased, more momentum is added to the shear layer, and thus the reattachment point is pushed further downstream from the separation point on the body. The size of the smaller vortices also depended on Reynolds number, and at the lowest Reynolds number the smaller afterbody vortex disappeared.

Heat-transfer distributions normalized by the computed stagnation point values for each of the three Reynolds number test cases are plotted in Figs. 11 and 12. The computed distributions are shown on a $\log$ scale plot in Fig. 11, while the details of the forebody and wake distributions are shown separately on linear scale plots in Figs. 12a and 12b. As in the experiments, the Reynolds number had no effect on the normalized forebody heating distribution (the slight spread in the forebody distributions is attributed to the use of the same boundary layer grid spacing for each of the three different Reynolds number cases), while in the wake, the normalized peak sting heating increased with Reynolds number.

\section{Comparison of Experiment and Computations}

Experimental and computational heating distributions for each of the three Reynolds numbers are compared in Figs. 13-15. The dimensional values for the experimental heating are extrapolated to the uniform $300 \mathrm{~K}$ wall temperature of the computations from the Stanton number defined in Eq. (10). Uncertainty bounds shown in these figures are based on the uncertainty analysis discussed previously.

Agreement between the two sets of distributions was very good on the forebody for all test cases. Computed heating rates were consistently higher than the experimental data, but remained within or just slightly outside of the estimated experimental uncertainty bounds.

In contrast to the forebody results, computational and experimental wake heating distributions differed significantly. Fair agreement was achieved on the afterbody and on the sting close to the model; however, the two distributions begin to diverge just upstream of the point where the free shear layer reattaches to the sting. Furthermore, while computed peak sting heating rates varied with Reynolds number to from $6 \%$ to $8 \%$ of the stagnation point heating, the experimental values ranged from $8 \%$ to $15 \%$ of the stagnation point heating. It was theorized that the divergence of the experimental and computational results was due to the growth of turbulence in the reattached boundary layer on the sting, and that transition occurred just upstream of the free shear layer reattachment point (Fig. 16), which is where the heating distributions begin to differ.

While transition had a large effect on the flow downstream of reattachment, it had little effect on the flow within the wake vortex since the favorable pressure gradient produced as the reversed flow within the vortex accelerates from rest at the reattachment stagnation point tends to dissipate turbulence ingested into the wake vortex. For this reason, the computed laminar heating distributions upstream of reattachment and the computed vortex sizes agree fairly well with the experimental data.

The theory that the reattachment region is where transition occurs is based on studies by Lees ${ }^{28}$, Demetriades $^{29}$, and Zeiberg ${ }^{30}$. In these studies, it was observed that at low Reynolds numbers, transition first occurs far downstream from the reattachment point (or from the neck of the wake in the case of an actual vehicle, which would not have a sting and reattachment point). As the Reynolds number is increased, the transition point moves upstream until it reaches the reattachment point (or neck). Because of the increasing pressure gradient which is caused as the flow is decelerated and turned at reattachment, the reattachment region acts as a trigger for transition, and so the transition point remains fixed here across a wide range of Reynolds numbers. Eventually, the Reynolds number is high enough for transition to occur in the free shear layer, and the transition point begins to move upstream within the free shear layer.

Comparisons between the computed streamlines and the oil flow photographs support the hypothesis that transition occurs near the reattachment point. Although the laminar computations predict a small downstream movement of the separation point with Reynolds number and the oil flow photographs reveal a small upstream movement, the actual locations were quite close (Fig. 17), which suggests that 
transition cannot be occurring very far upstream of reattachment. Furthermore, the computed and observed locations of the boundary layer separation on the afterbody of the model are also close, which would suggest that the attached boundary layer on the model is laminar, as does the good agreement between measured and predicted heating distributions on the forebody experiment.

The transition of the free shear layer to turbulent flow and the location of the transition point have been presented as hypotheses. Transition appears to be the best explanation for the discrepancies between predicted and measured heating levels on the sting, which are much greater than the estimated experimental uncertainty. However, without flow field diagnostics such as hot-wire surveys, or schlieren or electron beam photography, which were not available in this study, definitive conclusions about the state of the free shear layer cannot be made. Nevertheless, two other possible causes of disagreement between experiment and computation can be eliminated. These are the computational grid structure and rarefaction effects in the wake.

While it has been shown that the wake computations can be very sensitive to the grid structure, all grid adaptations and grid resolution increases performed in this work had the effect of lowering the heating on the sting and moving the reattachment point further downstream. That is, optimization of the wake grid further increased the differences between computational and experimental results. Therefore, the grid structure cannot be the cause of the differences between experiment and computation.

However, in regard to grid structure, it is important to note that the magnitudes of the computed laminar heating rates on an original, unadapted grid (Fig 9b.) are comparable to those of the turbulent data (Fig. 13b). Since laminar computations on non-optimized grids may, incorrectly, be in qualitative agreement with turbulent data, comparisons with these computations could lead to incorrect conclusions about the state of the wake. An unpublished preliminary comparison with computational results from a non-optimized grid was one of the reasons that the experimental data discussed in the present paper were originally thought to result from a laminar wake ${ }^{4}$. While other issues such as flow quality, rarefaction effects, and thermochemical models in the CFD codes must also be investigated, the grid structure should also be considered as one of the possible reasons for the disagreement seen in wake heating comparisons such as Refs. 10 and 13.

In order to confirm that the Navier-Stokes equations for continuum flow were applicable for the low density flow in the wake of the model, local Knudsen number contours were computed. The local Knudsen number is given by:

$$
K_{n}=\frac{\lambda_{M F P}}{\rho}|\nabla \rho|
$$

where the mean free path is:

$$
\lambda_{M F P}=\frac{1}{\sqrt{2} \pi d^{2} N}
$$

According to $\mathrm{Bird}^{31}$, the continuum assumption begins to break down for local Knudsen numbers above 0.1 , and for values above 0.2 the Navier-Stokes equations are no longer valid.

Local Knudsen number contours for the three cases are shown in Figs. 18-20. At the high and intermediate Reynolds number cases, the local Knudsen numbers reach 0.1 only in a thin region near the separation point, while the local Knudsen number reaches the 0.2 level only in a small area around the separation point for the lowest Reynolds number case. Therefore, the Navier-Stokes equations are considered to be appropriate for the conditions of this study

\section{Summary and Conclusions}

Experiments and computations have been performed for a 70-deg sphere-cone entry vehicle geometry at Mach 10. The experiments were conducted in a perfect-gas wind tunnel, and the computations were made using a laminar, axisymmetric/2D Navier-Stokes solver with a perfect-gas thermochemical model. Comparisons were made between heating distributions from the experiments and computations. Agreement of the heating distributions to within the experimental uncertainty was achieved on the forebody of the model. In the wake, the experimental heating data began to diverge from the computational results just upstream of the free shear layer reattachment point on the sting. Computed peak heating rates on the sting varied with Reynolds number from $6 \%$ to $8 \%$ of the forebody stagnation point heating, while the peak sting heating from the experiment varied from $8 \%$ to $15 \%$ of the stagnation point heating. From these comparisons, it was concluded that in the experiments transition to turbulence in the wake occurred in the vicinity of the 
free-shear-layer reattachment point on the model support sting.

\section{Acknowledgements}

This research was funded under NASA grants NAGW-1331 and NAG1-1663 to North Carolina State University.

\section{References}

${ }^{1}$ Bourke, R. D., Golombek, M. P., Spear, A. J., and Sturms, F. M., "MESUR and its Role in an Evolutionary Mars Exploration Program," IAF Paper 92-0509, 1992.

2 Hollis, B. R., and Perkins, J. N., "High-Enthalpy Aerothermodynamics of a Mars Entry Vehicle, Part 1: Experimental Results," to be published in AIAA Journal of Spacecraft and Rockets, Vol 34. No. 4., July-August 1997.

3 Hollis, B. R., and Perkins, J. N., "High-Enthalpy Aerothermodynamics of a Mars Entry Vehicle, Part 2: Computational Results," to be published in AIAA Journal of Spacecraft and Rockets, Vol 34. No. 4., July-August 1997.

${ }^{4}$ Hollis, B. R., and Perkins, J. N., "High-Enthalpy and Perfect-Gas Heating Measurements on a Blunt Cone," AIAA Journal of Spacecraft and Rockets, Vol. 33, No. 5, Sept.-Oct. 1996, pp. 628-635.

5 Hollis, B. R. "Experimental and Computational Aerothermodynamics of a Mars Entry Vehicle," Ph. D. Dissertation, Dept. of Mechanical and Aerospace Engineering, North Carolina State University, Dec. 1996. Also available under same title as NASA CR 201633, Dec. 1996.

${ }^{6}$ Horvath, T. J., McGinley, C. B., and Hannemann, K., "Blunt Body Near Wake Flow Field at Mach 6," AIAA Paper 96-1935, June 1996.

${ }^{7}$ Horvath, T. J. and Hannemann, K., "Blunt Body Near Wake Flow Field at Mach 10," AIAA Paper 97-0986, Jan. 1997.

${ }^{8}$ Kastell, D., Horvath, T. J., and Eitelberg, G., "Nonequilibrium Flow Expansion Around a Blunted Cone," 2nd European Symposium on Aerothermodynamics, ESA/ESTEC, Noordwijk, The
Netherlands, Nov., 1994.

${ }^{9}$ Mitchletree, R. A., and Gnoffo, P. A., "Wake Flow About a MESUR Mars Entry Vehicle," AIAA Paper 94-1958, June 1994.

${ }^{10}$ Haas, B. L., and Venkatapathy, E., "Mars Pathfinder Computations Including Base-Heating Predictions," AIAA Paper 95-2086, June 1995.

${ }^{11}$ Gochberg, L. A., Allen, G. A., Gallis, M. A., and Deiwert, G. S., "Comparison of Computations and Experiments for Nonequilibrium Flow Expansions Around a Blunted Cone," AIAA Paper 96-0231, Jan. 1996.

${ }^{12}$ Allegre, J., and Bisch, D., "Blunted Cone at Rarefied Hypersonic Conditions. Experimental Density Flow Fields, Heating Rates and Aerodynamic Forces," Centre National de la Recherche Scientifique, Meudon, France, CNRS Report RC 95-2, Sept. 1995.

13 Holden, M., Kolly, J., and Chadwick, K., "Calibration, Validation and Evaluation Studies in the LENS Facility,” AIAA Paper 95-0291, Jan. 1995.

${ }^{14}$ Holden, M., Harvey, J., Boyd, I., George, J., and Horvath, T., "Experimental and Computational Studies of the Flow Over a Sting Mounted Planetary Probe," AIAA Paper 97-0768, Jan., 1997.

15 Moss, J. N., Price, J. M., Dogra, V. K., and Hash, D. B., "Comparison of DSMC and Experimental Results for Hypersonic External Flows," AIAA Paper 95-2028, June 1995.

16 Micol, J. R., "Hypersonic Aerodynamic/ Aerothermodynamic Testing Capabilities at Langley Research Center: Aerothermodynamic Facilities Complex," AIAA Paper 95-2107, June 1995.

17 Schultz., D. L., and Jones, T. V., "Heat Transfer Measurements in Short-Duration Hypersonic Facilities," NATO Advisory Group for Aerospace Research and Development, AGARD Rep. AG-165, Neuilly sur Seine, France, Feb. 1973.

18 Hollis, B. R., “User's Manual for the One-Dimensional Hypersonic Aero-Thermodynamic (1DHEAT) Data Reduction Code," NASA CR 4691, 
August, 1995.

${ }^{19}$ Kendall, D. N., Dixon, W. P., and Schulte, E. H., "Semiconductor Surface Thermocouples for Determining Heat-Transfer Rates," IEEE Transactions on Aerospace and Electronic Systems, Vol. AES-3, No. 4, July 1967, pp. 596-603.

${ }^{20}$ Hedlund, E. R., Hill, J. A. F., Ragsdale, W. C., and Voisinet, R. L. P., "Heat Transfer Testing in the NSWC Hypervelocity Wind Tunnel Utilizing Co-axial Surface Thermocouples," NSWC MP 80-151, March 1980.

21 "Assessment of Wind Tunnel Data Uncertainty," AIAA Standards Publication S-071, 1995.

22 Candler, G. V., and MacCormack, R. W., "Computation of Weakly Ionized Flows in Thermochemical Nonequilibrium," AIAA Journal of Thermophysics and Heat Transfer, Vol. 5, No. 3, pp. 226-273, 1991.

23 MacCormack, R. W. and Candler, G. V., "The Solution of the Navier-Stokes Equations Using GaussSeidel Line Relaxation," Computers \& Fluids, Vol. 17, No. 1, pp. 133-150, 1989.

24 Thompson, J. F., Thames, F. C., and Mastin, C. W., "Automatic Numerical Generation of Body-Fitted Curvilinear Coordinate System for Field Containing any Number of Arbitrary Two-Dimensional Bodies,"
Journal of Computational Physics, Vol. 15, pp. 299319, 1974.

${ }^{25}$ Steger, J. L. and Sorenson, R. L., "Automatic MeshPoint Clustering Near a Boundary in Grid Generation with Elliptic Partial Differential Equations," Journal of Computational Physics, Vol. 33, pp. 405-410, 1979.

26 Gnoffo, P. A., Hartung, L. C., and Greendyke, R. B., "Heating Analysis for a Lunar Transfer Vehicle at Near-Equilibrium Flow Conditions," AIAA Paper 930270, January 1993.

27 Alter, S. J., "The Volume Grid Manipulator (VGM): A Grid Reusability Tool," NASA CR 4772, April 1997.

${ }^{28}$ Lees, L., "Hypersonic Wakes and Trails," AIAA Journal, Vol. 2, No. 3, pp. 417-428, March 1964.

29 Demetriades, A. "Hot-Wire Measurement in the Hypersonic Wakes of Slender Bodies," AIAA Journal, Vol. 2, No. 2, pp. 245-250, Feb. 1964.

30 Zeiberg, S. L., "Transition Correlations for Hypersonic Wakes and Trails," AIAA Journal, Vol. 2, No. 3, pp. 564-565, March 1964.

31 Bird, G. A., Molecular Gas Dynamics and the Direct Simulation of Gas Flows, Clarendon, Oxford, England, UK, 1994.

Table 1: 31-Inch Mach 10 Air Tunnel Test Conditions

\begin{tabular}{cccc}
\hline \hline & $\mathbf{R e}_{\mathbf{1 , \mathbf { D }}}=\mathbf{8 . 2 3 \times 1 \mathbf { 1 0 } ^ { \mathbf { 4 } }}$ & $\mathbf{R e}_{\mathbf{1 , \mathbf { D }}}=\mathbf{1 . 6 2 \times 1 0 ^ { \mathbf { 5 } }}$ & $\mathbf{R e}_{\mathbf{1 , \mathbf { D }}}=\mathbf{3 . 1 5 \times 1 0 ^ { \mathbf { 5 } }}$ \\
\hline $\mathbf{P}_{\mathbf{1}}(\mathbf{P a})$ & 69.0 & 130.6 & 242.0 \\
$\mathbf{T}_{\mathbf{1}}(\mathbf{K})$ & 53.31 & 52.45 & 51.48 \\
$\rho_{\mathbf{1}}\left(\mathbf{k g} / \mathbf{m}^{\mathbf{3}}\right)$ & 0.00451 & 0.00868 & 0.01646 \\
$\mathbf{U}_{\mathbf{1}}(\mathbf{m} / \mathbf{s e c})$ & 1416 & 1422 & 1425 \\
$\mathbf{M}_{\mathbf{1}}$ & 9.675 & 9.795 & 9.928 \\
$\mathbf{h}_{\mathbf{0}}-\mathbf{h}_{\mathbf{2 9 8}}(\mathbf{M J} / \mathbf{k g})$ & 0.756 & 0.764 & 0.767 \\
$\mathbf{p}_{\mathbf{0 , 2}}$ & 8383 & 16280 & 31000 \\
$\mathbf{T}_{\mathbf{0 , 2}}$ & 1008 & 1015 & 1017 \\
\hline \hline
\end{tabular}




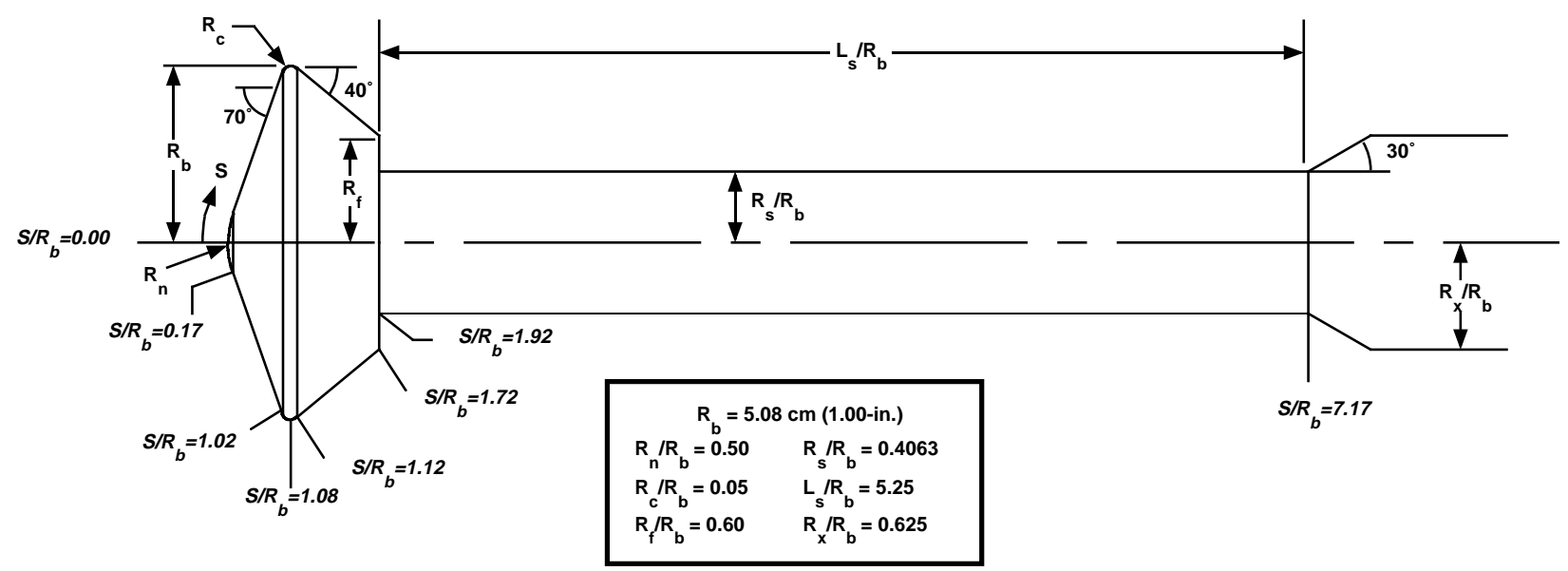

Figure 1. Entry Vehicle Model Geometry

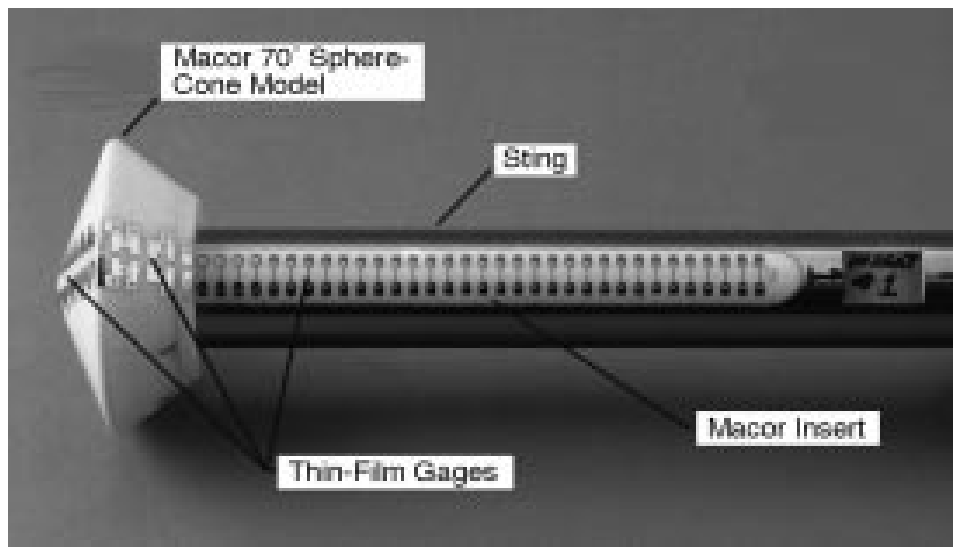

Figure 2. Entry Vehicle Test Model Photograph

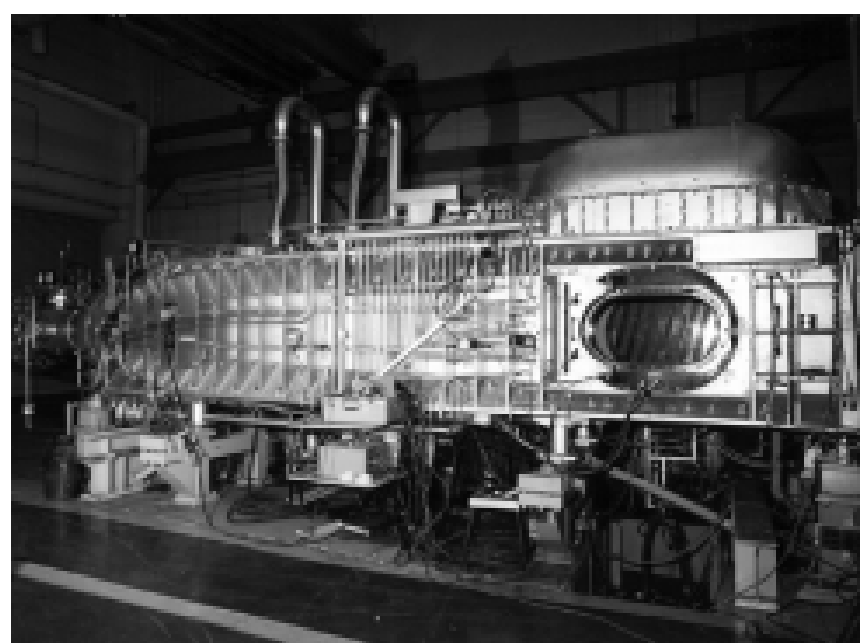

Figure 3. 31-Inch Mach 10 Air Tunnel

9

American Institute of Aeronautics and Astronautics 


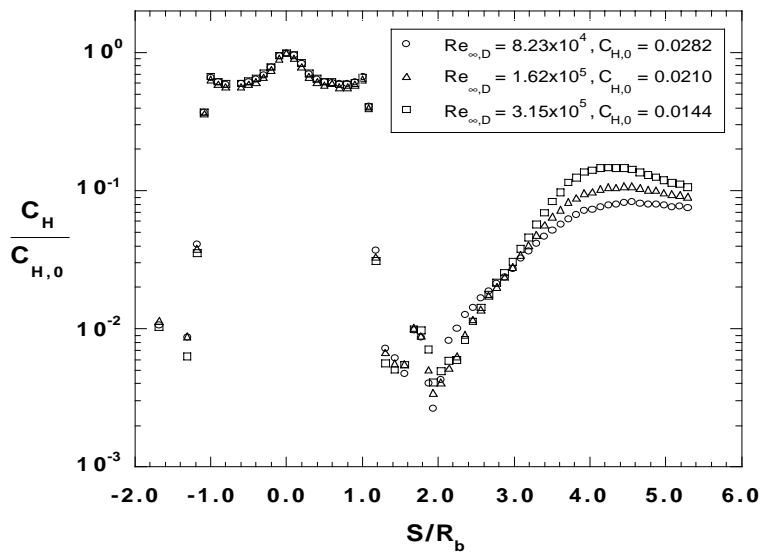

Figure 4. Reynolds Number Effects on Experimental Heating Distributions

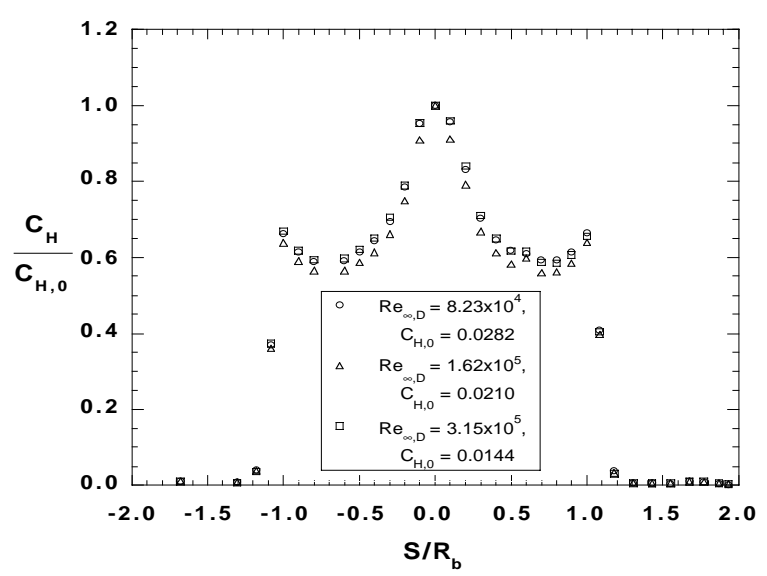

Figure 5a. Reynolds Number Effects on Experimental Heating Distributions - Forebody Details

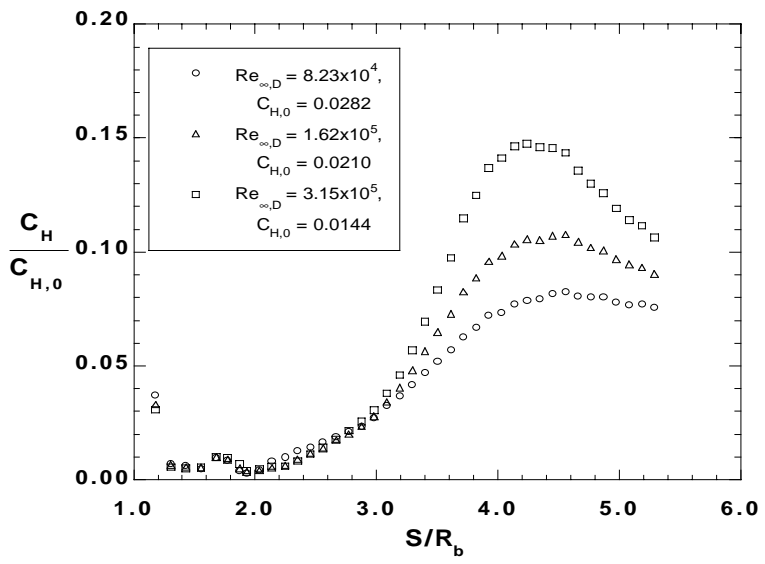

Figure 5b. Reynolds Number Effects on Experimental Heating Distributions - Wake Details

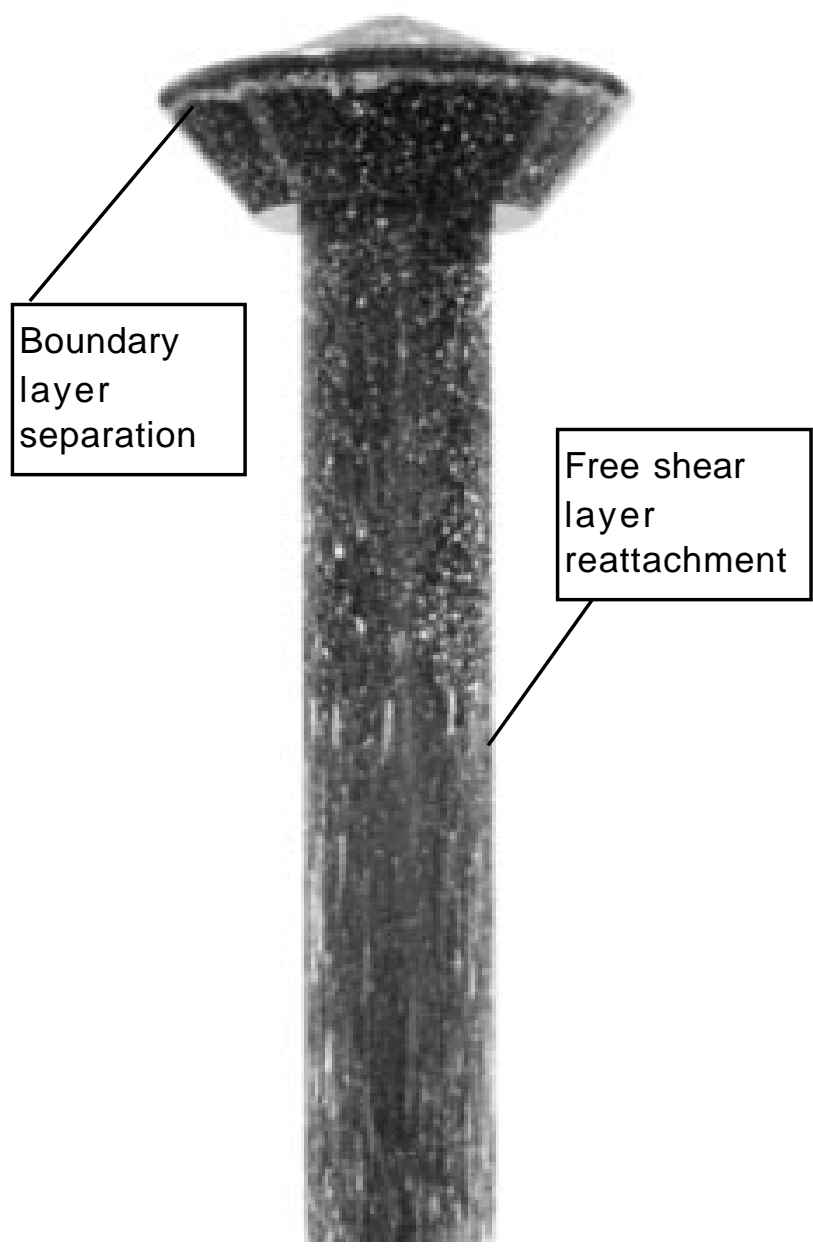

Figure 6. Sample Surface Oil Flow Patterns, $\operatorname{Re}_{1, \mathrm{D}}=8.23 \times 10^{4}$ 


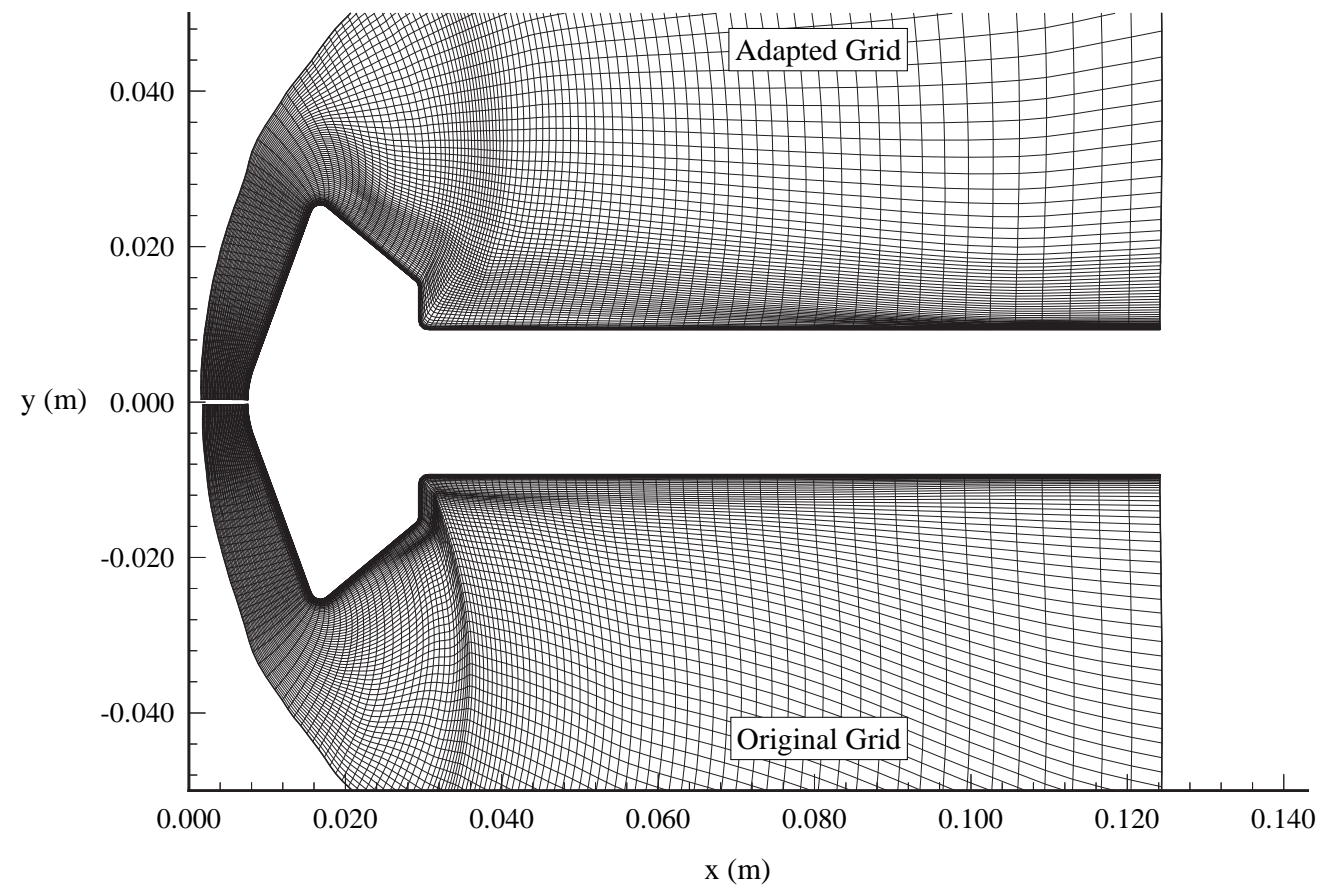

Figure 7: Shock-Aligned Grids Before and After Wake Adaptation Using VGM, $\operatorname{Re}_{1, \mathrm{D}}=8.23 \times 10^{4}$

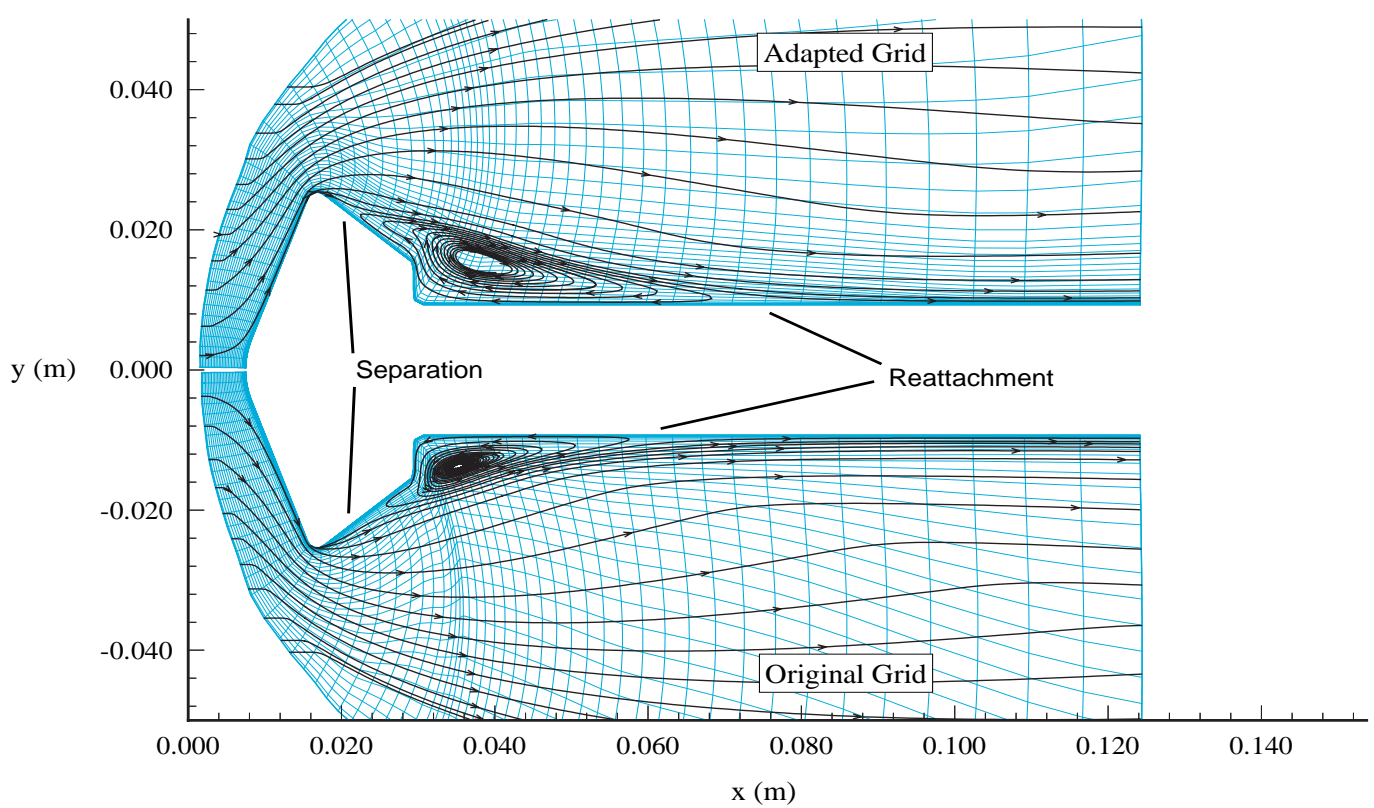

Figure 8. Effects of Grid Adaptation on Wake Flow, $\operatorname{Re}_{1, \mathrm{D}}=8.23 \times 10^{4}$

11

American Institute of Aeronautics and Astronautics 


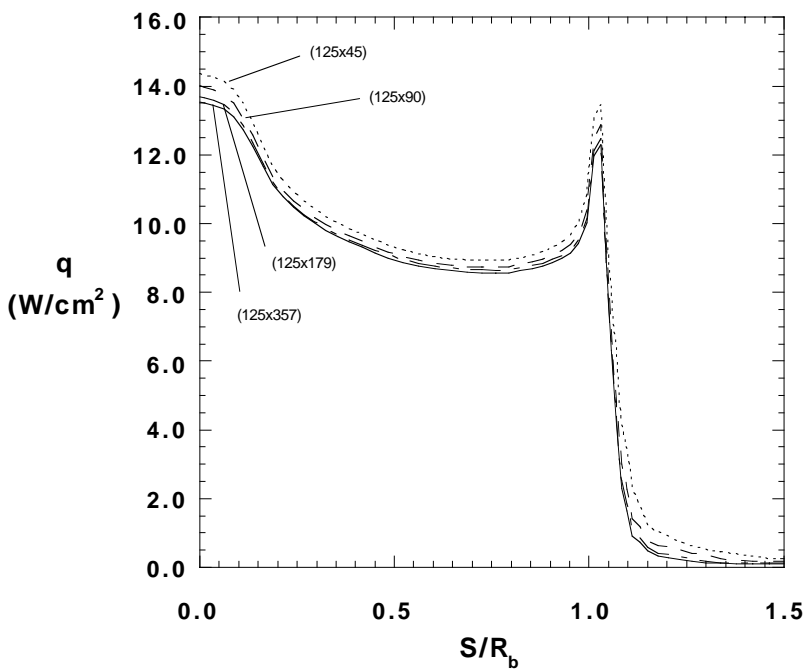

Figure 9a. Grid Resolution Effects on Computed Forebody Heating Distributions, $\operatorname{Re}_{1, \mathrm{D}}=8.23 \times 10^{4}$

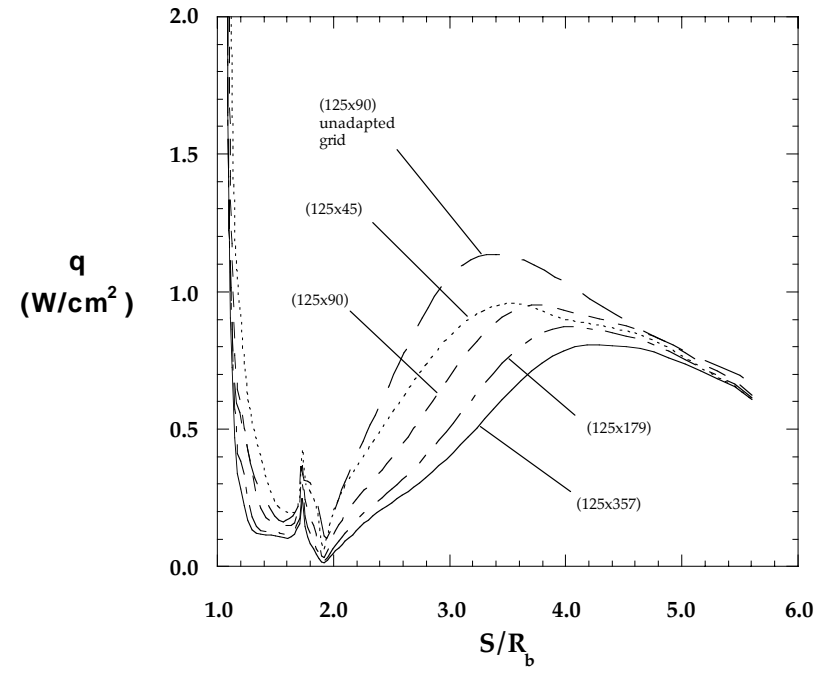

Figure 9b. Grid Resolution and Grid Adaptation Effects on Computed Wake Heating Distributions, $\operatorname{Re}_{1, \mathrm{D}}=8.23 \times 10^{4}$

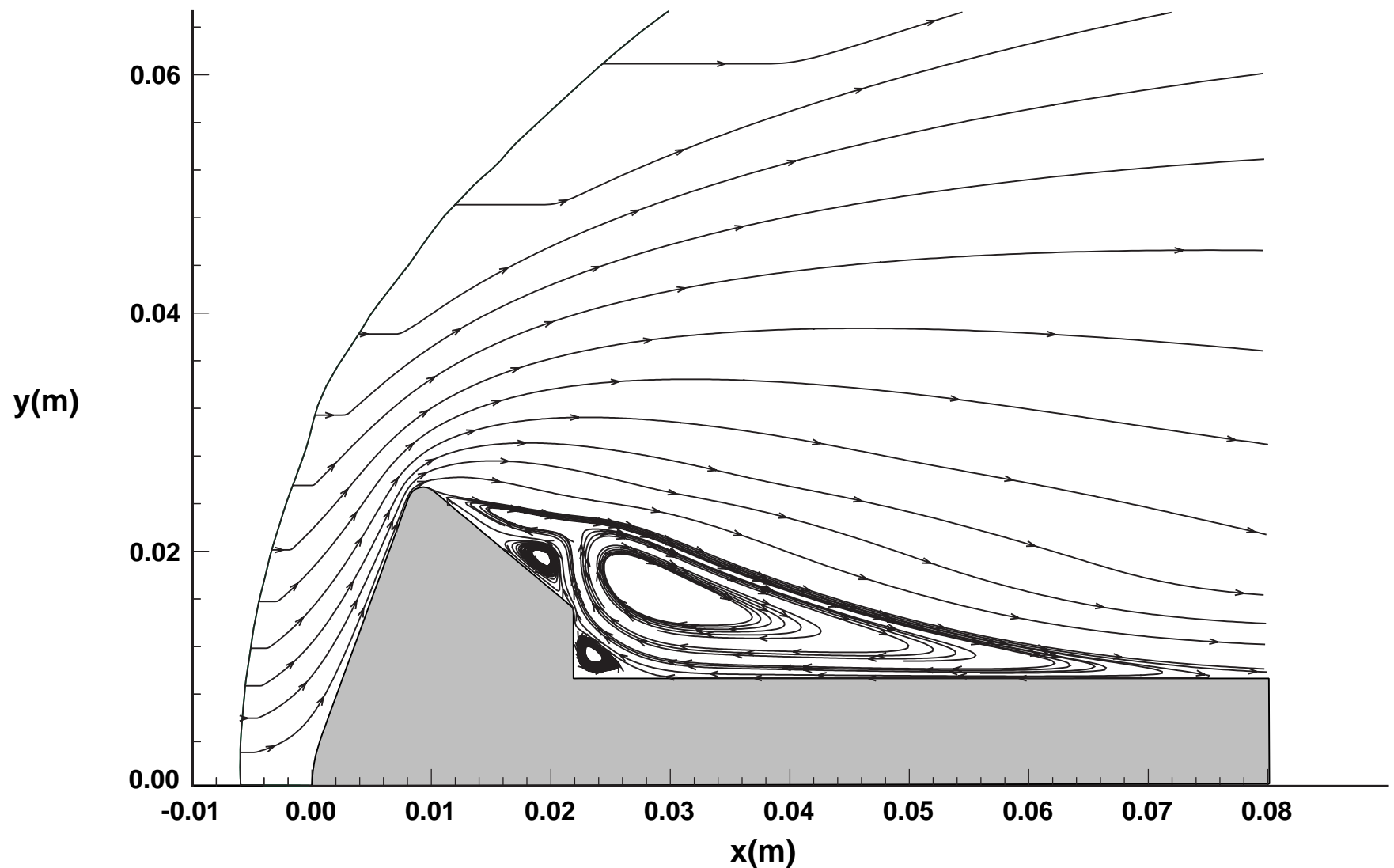

Figure 10. Sample Computed Wake Streamlines, $\operatorname{Re}_{1, \mathrm{D}}=8.23 \times 10^{4}$

12

American Institute of Aeronautics and Astronautics 


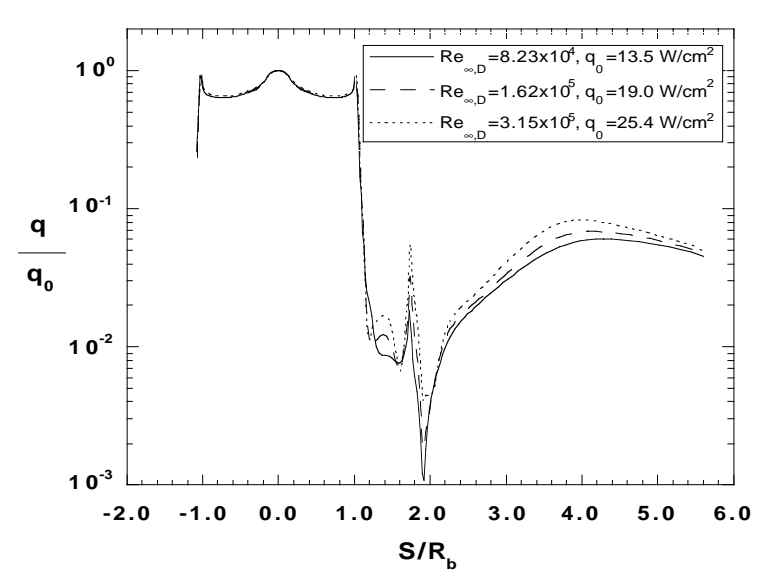

Figure 11. Reynolds Number Effects on Computed Heating Distributions

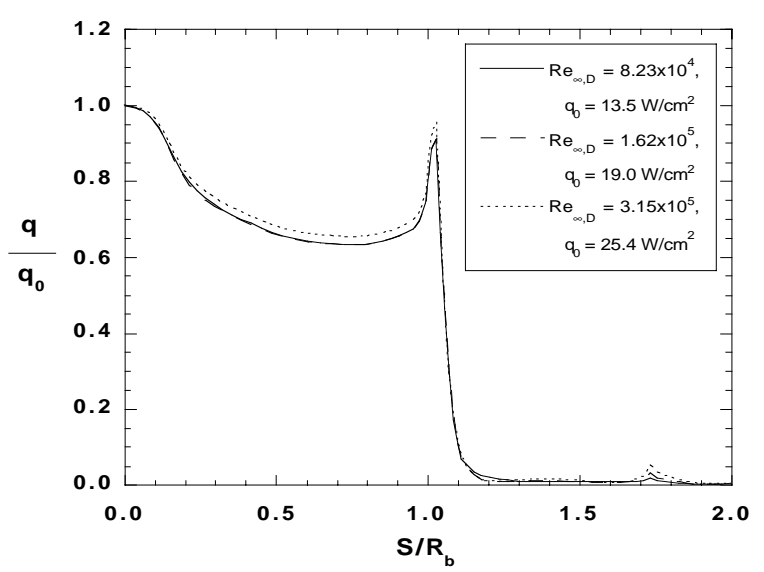

Figure 12a. Reynolds Number Effects on Computed Heating Distributions - Forebody Details

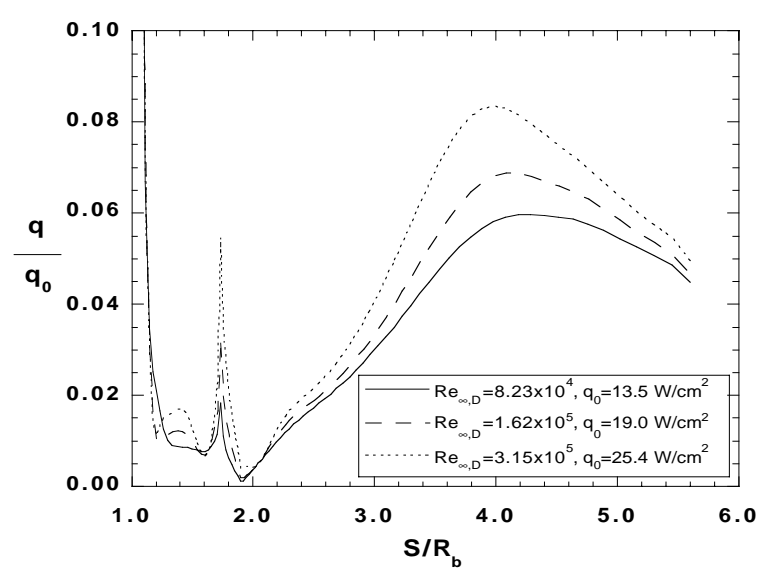

Figure 12b. Reynolds Number Effects on Computed Heating Distributions - Wake Details

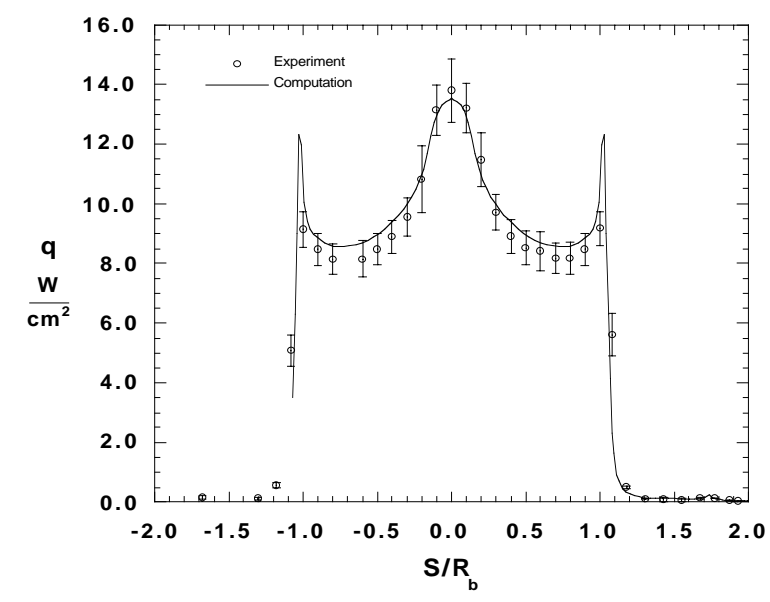

Figure 13a. Experiment vs. Computation,

Forebody Heating, $\operatorname{Re}_{1, \mathrm{D}}=8.23 \times 10^{4}$

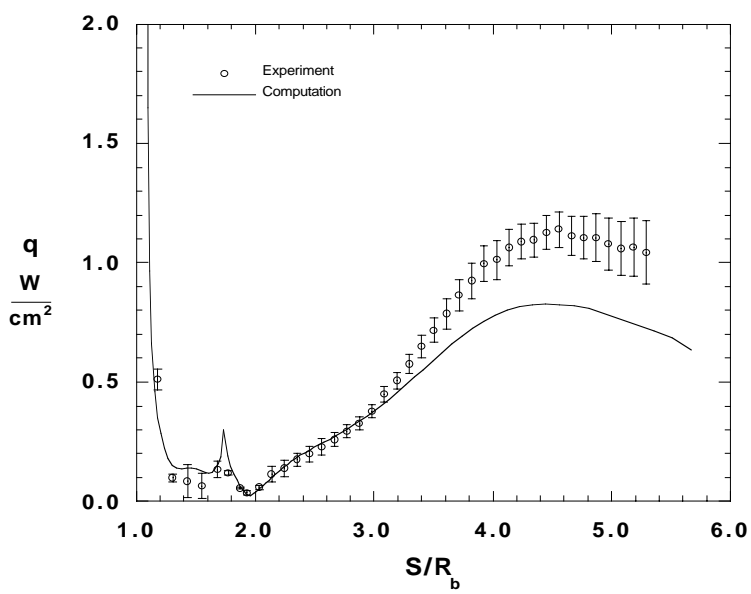

Figure 13b. Experiment vs. Computation, Wake Heating, $\operatorname{Re}_{1, \mathrm{D}}=8.23 \times 10^{4}$

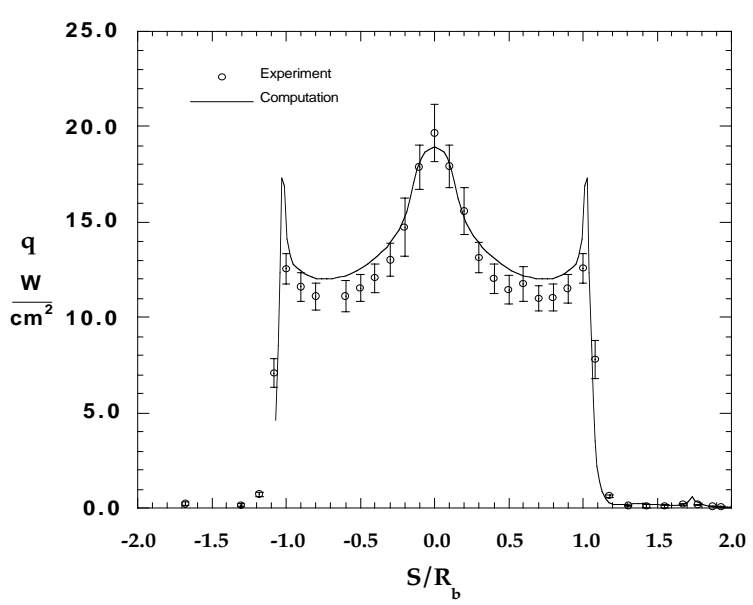

Figure 14a. Experiment vs. Computation, Forebody Heating, $\operatorname{Re}_{1, \mathrm{D}}=1.52 \times 10^{5}$

13

American Institute of Aeronautics and Astronautics 


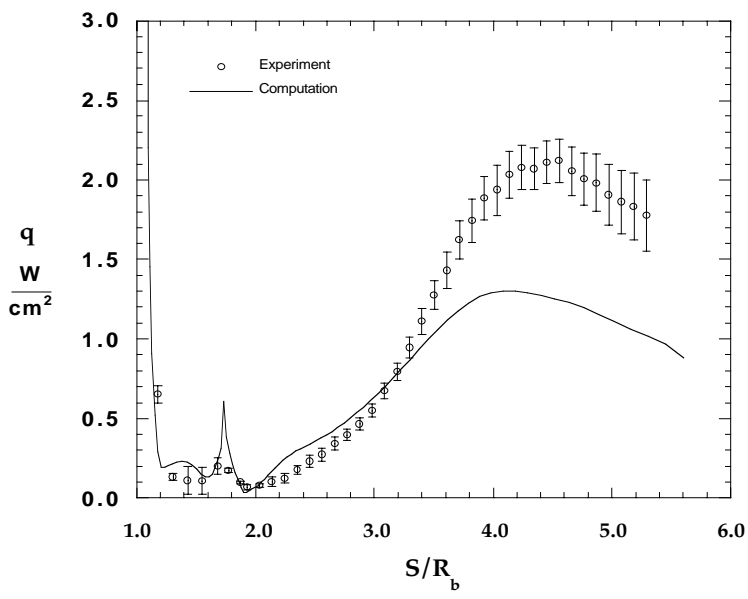

Figure 14b. Experiment vs. Computation, Wake Heating, $\operatorname{Re}_{1, \mathrm{D}}=1.52 \times 10^{5}$

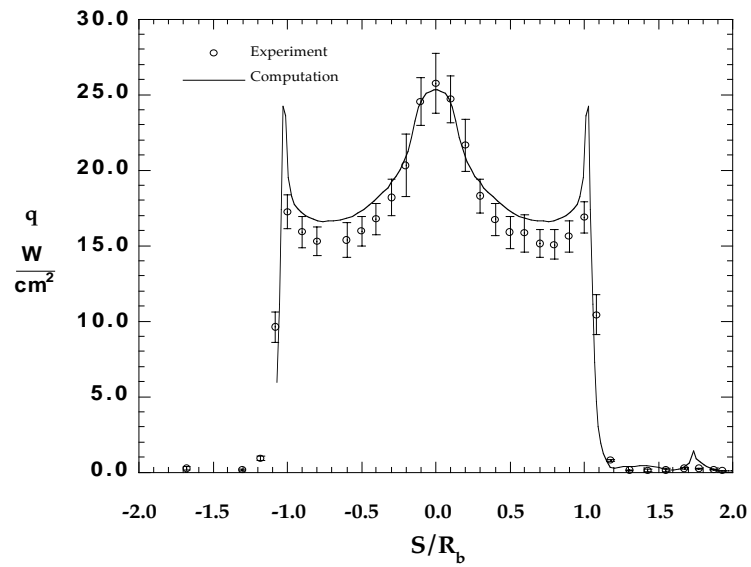

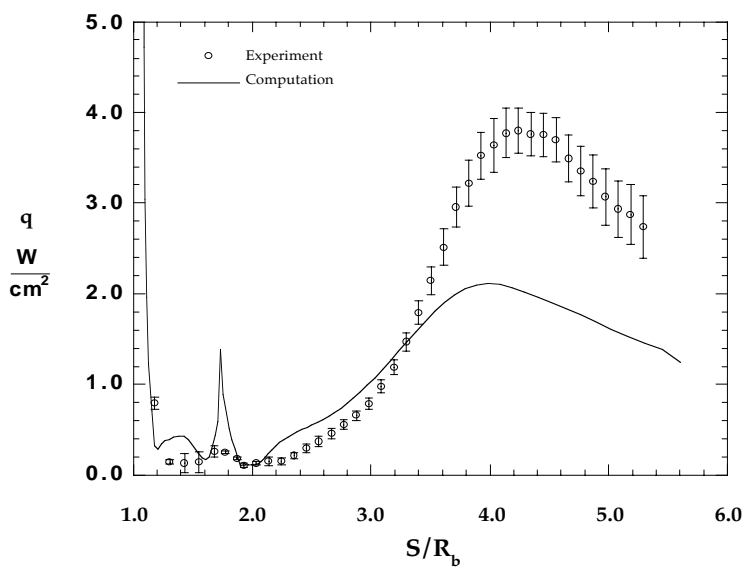

Figure 15b. Experiment vs. Computation, Wake Heating, $\operatorname{Re}_{1, \mathrm{D}}=3.15 \times 10^{5}$

Figure 15a. Experiment vs. Computation,

Forebody Heating, $\operatorname{Re}_{1, \mathrm{D}}=3.15 \times 10^{5}$

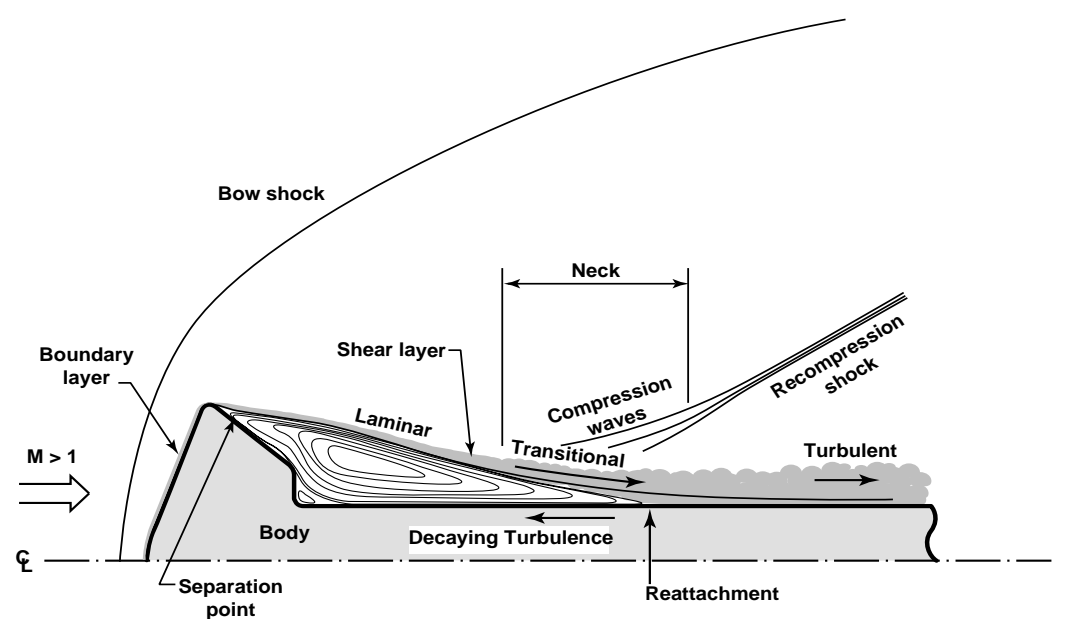

Figure 16. Transition in Blunt Body Wake Free Shear Layer

14

American Institute of Aeronautics and Astronautics 


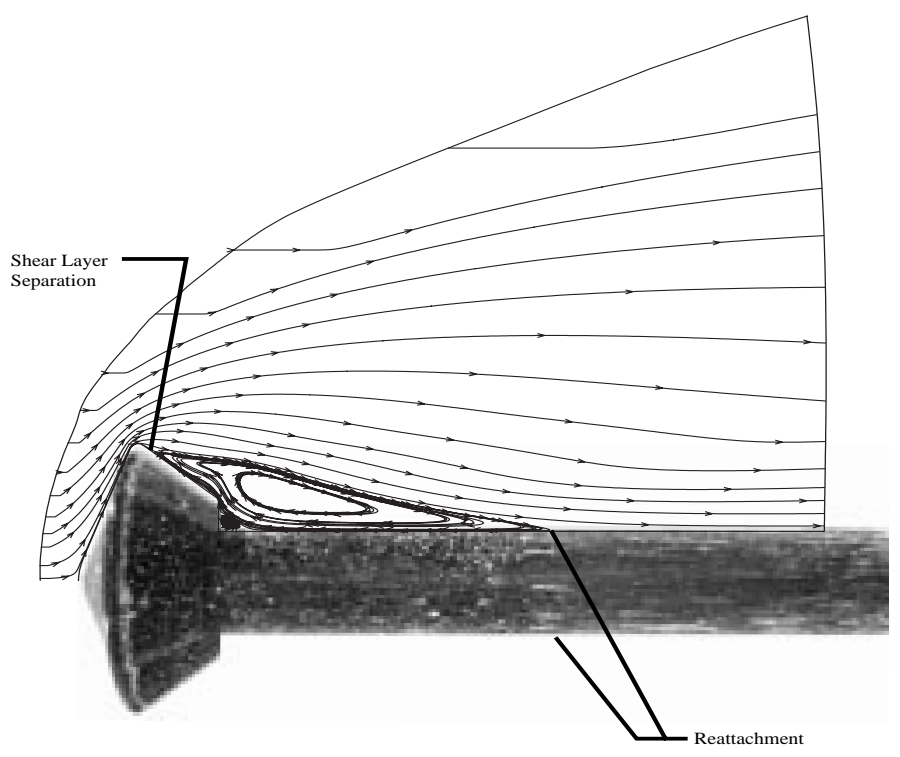

Figure 17. Computed Streamlines vs. Oil Flow Patterns, $\operatorname{Re}_{1, \mathrm{D}}=8.23 \times 10^{4}$

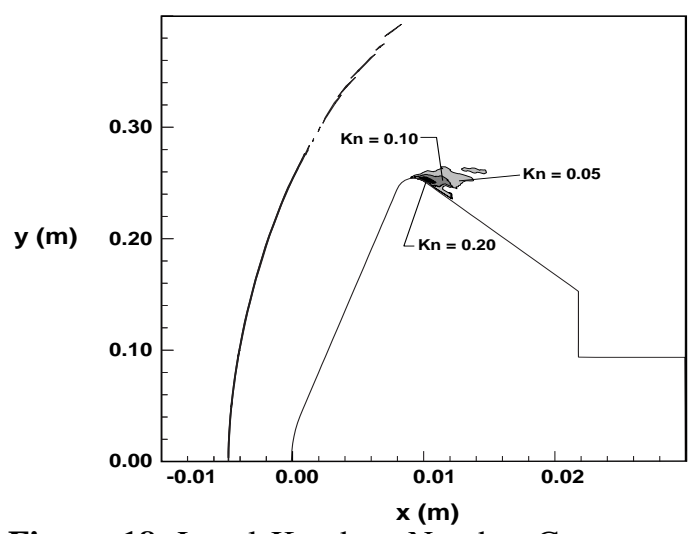

Figure 18. Local Knudsen Number Contours,

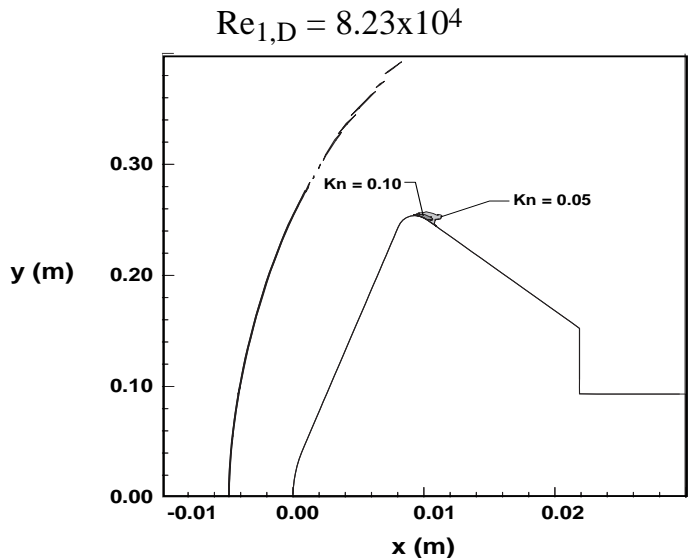

Figure 19. Local Knudsen Number Contours,

$$
\operatorname{Re}_{1, \mathrm{D}}=1.62 \times 10^{5}
$$

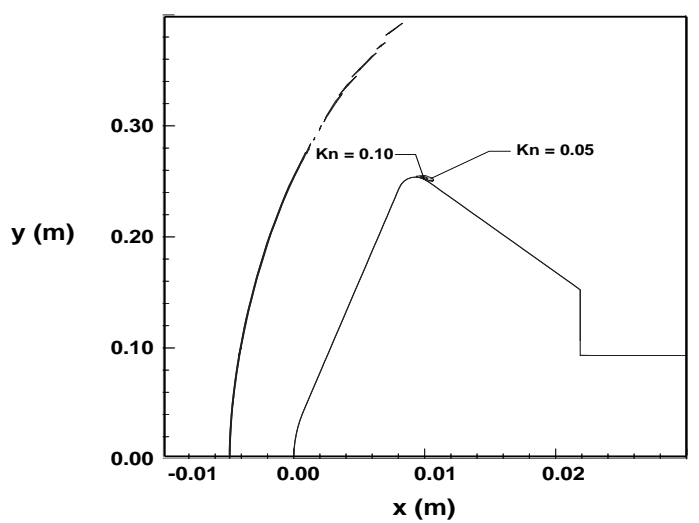

Figure 20. Local Knudsen Number Contours, $\operatorname{Re}_{1, \mathrm{D}}=3.15 \times 10^{5}$

15

American Institute of Aeronautics and Astronautics 